\title{
Invandringsförloppet hos vitstjärnig blåhake Luscinia svecica cyanecula på svenska västkusten
}

\section{Immigration process of White-spotted Bluethroat Luscinia svecica cyanecula at the Swedish west coast}

\author{
Reino Andersson \\ Rödaledstigen 6, 43253 Varberg, Sweden | samreinoandersson@gmail.com
}

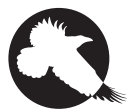

White-Spotted bluethroat Luscinia svecica cyanecula is the latest addition to the Swedish bird fauna, with the first breeding in Scania in 2015. There were only three records on the Swedish West Coast north of Scania through 2016 and the first breeding was reported in 2018. Censuses performed in 2020 and 2021 revealed 12 and 17 singing males, respectively. Out of 39 singing males 2017-2021, 36 were found in Halland. Most birds were found in coastal wetlands with reedbeds, to which they arrived mainly in April. Nine males represented breeding pairs and second clutches were later observed for four breeding pairs. The Swedish expansion should be seen in the context of Danish immigration in combination with a large-scale advance via the Netherlands and Germany. The White-spotted Bluethroat belongs to those range-expanding taxa that are expected to increase due to warmer climate. As there is plenty of appropriate habitats, not least rapeseed fields, the conditions favour a continued range expansion in southern Sweden.

Keywords: range expansion | climate change | Phragmites australis | Brassica napus | wetlands | agricultural landscape

\section{Introduktion}

Vitstjärnig blåhake Luscinia svecica cyanecula utgör en underart av blåhake och är det senaste tillskottet i den svenska fågelfaunan. Dess huvudsakliga utbredningsområde sträcker sig från Nederländerna österut till Polen, Ungern och Vitryssland. Den pågående expansionen i Nordvästeuropa har haft ett påfallande likartat förlopp som det för svarthakad buskskvätta (jfr Nyegaard m. fl. 2014, Andersson 2019). Den vitstjärniga blåhaken tillhör de taxa på frammarsch som brukar 
förknippas med klimatförändringen och som förväntas öka i utbredning enligt prognoser för den framtida fågelfaunan (Huntley m. fl. 2007, Haas m.fl. 2014).

I Nederländerna registrerades cirka 1000 par vitstjärniga blåhakar under inventeringar i mitten av 1970-talet. Tjugo år senare uppskattades numerären till 11 ooo och idag ligger antalet på över 20000 revirhävdande hannar (van Kleunen m. fl. 2017). Från att ha inskränkt sig till några få par i Danmark i början av 1990-talet, kunde man 2017 räkna in 700 revir (Vikstrøm \& Moshøj 2020).

Biotopval och uppträdande under häckningstid skiljer sig väsentligt från blåhakar av den nordliga "rödstjärniga" nominatformen svecica. De vitstjärniga föredrar vassbälten, blöta diken, kanaler och stränder, gärna med inslag av buskar. Utöver igenväxta sjöar och våtmarker förekommer den även i fält av raps Brassica napus (t. ex. Gedeon m. fl. 2014).

Det första fyndet i Sverige gjordes så sent som 1943, då en sjungande hanne uppehöll sig några veckor vid Oset i Närke (Rosenberg 1943). Därefter påträffades underarten vid ytterligare 18 tillfällen fram till 1970. Antalet fynd under den påföljande trettioårsperioden uppgick till 32, med en spridning ända upp till Norrbotten. Åren 2000-2014 inrapporterades sju fåglar, samtliga hannar iakttagna på våren (https://birdlife.se/ $\mathrm{rk} /$ raritetskatalogen).

På Västkusten gjordes den tidigaste observationen vid Getterön den 4-7 september 1959. Därefter föreligger endast två fynd i Halland fram till och med 2016. Det rörde sig om en sjungande hanne vid Kålelund, Ölmevalla 11-12 maj 2006 och ett ringmärkt exemplar på ön Nidingen 15 maj 2009 (https://birdlife.se/rk/ raritetskatalogen).

Landets första säkerställda häckning konstaterades vid Farhultsviken i nordvästra Skåne 2015, där en hanne påträffats sjungande redan året före. Där uppehöll sig minst tre permanenta revirhävdande hannar och åtminstone några honor, som vid flera tillfällen sågs med föda $\mathrm{i}$ näbben vid troliga bobesök (Klinteroth 2015, 2021).

Ytterligare tre sjungande hannar påträffades detta år, i Skåne, Småland och Närke. Sedan dess har vitstjärniga blåhakar observerats årligen vid Farhultsviken och ett ökat antal fynd har registrerats i landet så långt norrut som i Västerbotten. Bland dessa återfinns flera nya sångplatser i Skåne, där ytterligare häckningar

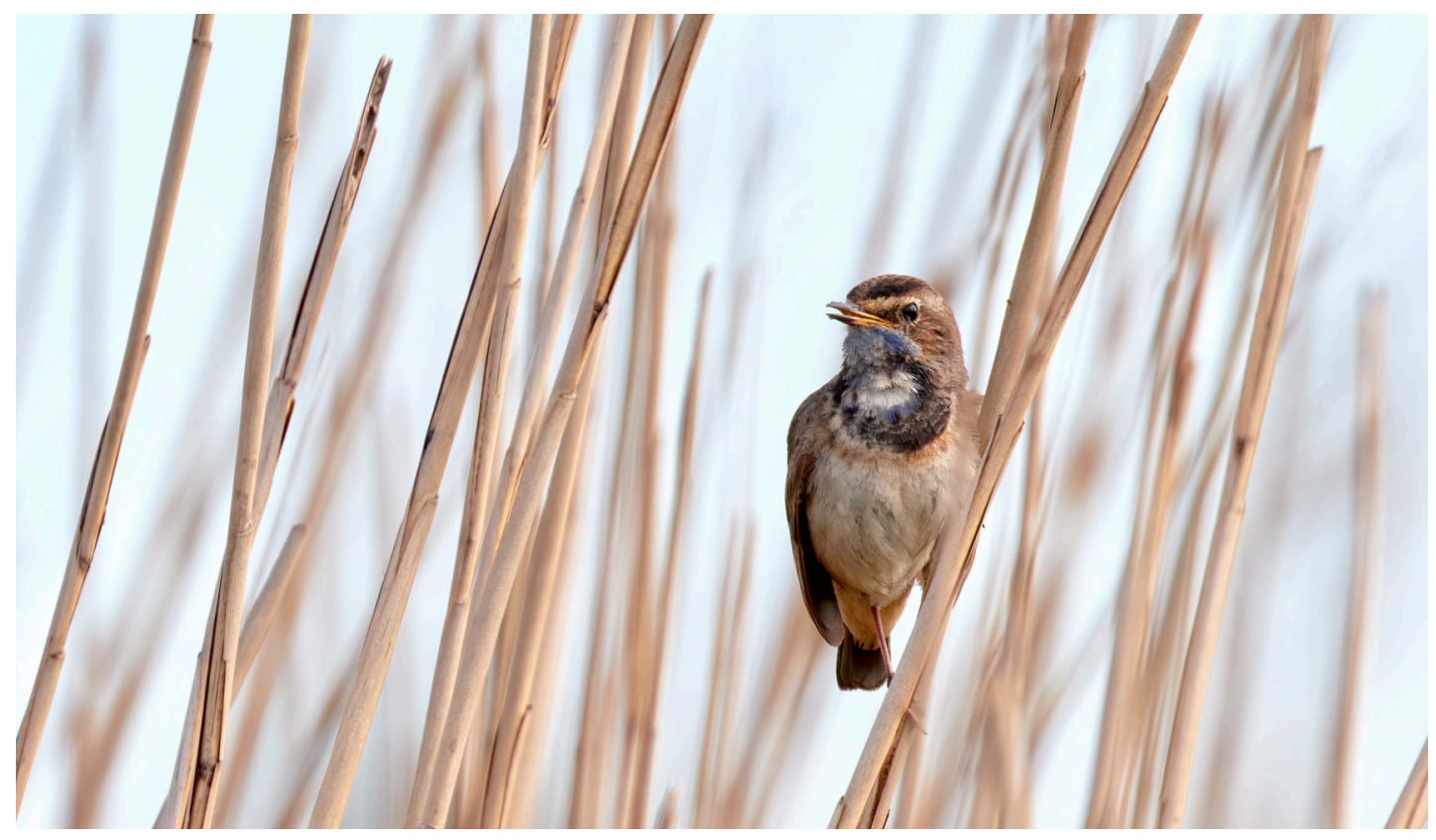

FIGUR 1. En av de nio häckande honorna av vitstjärnig blåhake Luscinia svecica cyanecula visade sig vid ån Törlans utlopp, Björkäng, 30 maj 2020. Foto: Stefan Johansson.

- One of the nine breeding females of White-spotted Bluethroat Luscinia svecica cyanecula observed in Törlan, Björkäng, 30 May 2020. Photo: Stefan Johansson. 
kunnat konstateras vid Farhultsviken, Löddesnäs och Krankesjön (Klinteroth 2021, https://birdlife.se/rk/ raritetskatalogen, https://www.artportalen.se, datauttag juli 2021).

Dräktkaraktärernas tillförlitlighet hos cyanecula och andra underarter (t. ex. vit strupfläck) har diskuterats i olika sammanhang (t. ex. Glutz von Blotzheim \& Bauer 1988, Johnsen m.fl. 2006, Duivendijk 2011, Shirihai \& Svensson 2018). Då en viss variation och överlappning förekommer, skulle enstaka exemplar på Västkusten teoretiskt kunna tillhöra L. s. svecica. Med utgångspunkt från hittills kända data förefaller det dock som högst osannolikt. Alla hannar (med tillhörande honor; figur 1) i detta material, som uppträtt med vit strupfläck i vassar och våtmarksmiljöer, behandlas därmed som cyanecula.

Denna uppsats dokumenterar invandringsförloppet under häckningstid (april-juli) på Västkusten norr om Skåne (Göteborg/ Bohuslän, Halland) under perioden 2017-2021. Resultatet är avsett att ligga till grund för framtida uppföljningar av artens populationsutveckling.

\section{Material och metoder}

Materialet för Västkusten som redovisas i denna uppsats grundar sig till stor del på spontana rapporter som inkommit till databasen Artportalen (https://www.artportalen.se) till och med juli 2021. Eftersom vitstjärnig blåhake tillhört en av landets ovanligaste fåglar, kan man förmoda att en hög andel av alla observationer blivit rapporterade. Artens förhållandevis tillbakadragna och dolda levnadsvanor kan dock leda till att de lätt förbises och underskattas vid en helhetsbedömning. Sångaktiviteten är som störst under den mörka delen av dygnet. Under de ljusa timmarna är det därför lätt att missa en fagel.

Först under 2020 skedde mer noggranna efterforskningar utöver den spontana rapporteringen. Häckningssäsongen 2021 bedrevs systematiska inventeringar utmed Västkusten. I Halland genomfördes riktade besök vid lämpliga och på förhand utsedda vassområden, både i kustbandet och i inlandet. Avlyssningarna i Göteborg/ Bohuslän var dock av mer sporadisk karaktär. Inventeringarna hade föregåtts av flera artiklar och upprop i Vår Fågelvärld, Fåglar i Halland och Fåglar på Västkusten (Andersson 2021a, 2021b, Magnander 2021). Dessutom hade ett antal initierade ornitologer vidtalats på förhand. För att öka inventeringseffektiviteten an- vändes i viss utsträckning ljuduppspelning, vilket visade sig vara av stor betydelse, i synnerhet då våren var ovanligt kall och verkade hämmande på sångaktiviteten.

Fynden delas upp i tillfälligt sjungande hannar, permanenta sångrevir och säkerställda häckningar. Med en tillfälligt sjungande hanne avses att uppehållstiden på en lokal har varit kortare än en vecka. Ett permanent sångrevir karakteriseras av att hannen påträffats sjungande under en period om minst en vecka. Klassningen av häckningsstatus följer de kriterier för säkerställd häckning (kategori 11-20) som anges i Svensk Fågelatlas (Svensson m.fl. 1999).

\section{Resultat}

\section{PERIODEN 2017-2019}

Häckningssäsongen 2017 påträffades totalt tre sjungande hannar, två på Getteröns Naturreservat och en i Halmstads hamn (Nord 2017). Hjälms våtmark i Kungsbacka kommun var den enda plats med registrerade vitstjärniga blåhakar under 2018. I gengäld konstaterades två sjungande hannar och Västkustens första häckning med två utflugna kullar. Det var dock ovisst om det handlade om en andrakull eller om båda hannar fött upp var sin kull. Här klassas de som en säkerställd häckning med två kullar och ett permanent sångrevir, för att undvika överskattning av antalet häckningar. På samma lokal konstaterades däremot en säker första- och andrakull 2019. Därutöver återfanns ett permanent sångrevir vid Lis mosse och tre tillfälligt sjungande hannar, vilket resulterade i totalt fem revir.

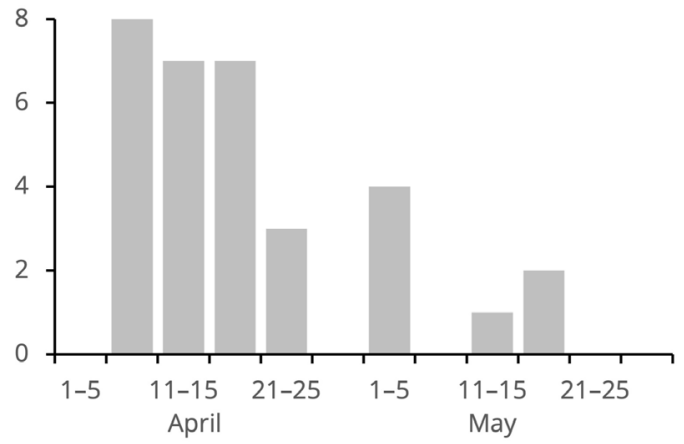

FIGUR 2. Observerat ankomstdatum för 32 sjungande hannar våren 2017-2021, fördelat på femdagarsperioder.

- Observed arrival date for 32 singing males during the springs of 2017-2021, divided into five-day periods. 
Därmed registrerades tio sjungande hannar under perioden 2017-2019 (tabell 1, figur 2). Dessutom fångades en hanne på Nidingen redan 6 april 2019.

\section{HÄCKNINGSSÄSONGEN 2020}

Detta år konstaterades Bohusläns första fynd av vitstjärnig blåhake vid Tofta kile 18 april, där även en hona iakttogs. Totalt inräknades 12 sjungande hannar under säsongen: tre tillfälligt sjungande, sex permanenta sångrevir och tre säkerställda häckningar. Fyndplatserna återfanns främst i Kungsbacka och Varbergs kommuner och häckningarna fördelades på Hjälms våtmark, Årnäs och ån Törlans utlopp (figur 3a). Blåhaken vid Lagaoset sågs aldrig, men har medtagits då den sjöng i skymningen tidigt på säsongen i april i ett lämpligt vassområde (tabell 1, figur 2, 3a).

\section{HÄCKNINGSSÄSONGEN 2021}

I Bohuslän påträffades två sjungande hannar, vid Ljungskile och i Harestad. Liksom föregående år hittades de flesta hannarna i kommunerna Kungsbacka och Varberg (figur $3 b$ ). Fem tillfälligt sjungande hannar, åtta permanenta sångrevir och fyra säkerställda häckningar resulterade i totalt 17 revir. Häckningarna konstaterades vid Hjälms våtmark, Forsbäck i Kungsbackafjorden, Björkängs camping och Vassvik, Ugglarp (figur 3b). Vid Hjälm sågs två ungkullar som klassats på samma sätt som 2018. Vid Björkäng konstaterades den andra säkra andrakullen. I Vassvik verifierades häckningen först efter att juvenila ungar setts utflugna i början av juli. Hannarna vid Kärrastrand och Norra Uddarna sågs alltför dåligt för att säkert kunna rasbestämmas, men har medtagits på samma grunder som

TABELL 1. Observerad närvaro av samtliga 39 sjungande hannar av vitstjärnig blåhake Luscinia svecica cyanecula 2017-2021. T (tillfälligt sjungande hanne), $\mathrm{P}$ (permanent sångrevir), $\mathrm{H}$ (säkerställd häckning).

- Observed presence in all 39 singing males of White-spotted Bluethroat Luscinia svecica cyanecula in 2017-2021. T (temporarily singing males), $P$ (permanent song territory), $H$ (confirmed breeding).

\begin{tabular}{|c|c|c|c|c|c|c|}
\hline $\begin{array}{l}\text { Kommun } \\
\text { Municipality }\end{array}$ & $\begin{array}{l}\text { Lokal } \\
\text { Site }\end{array}$ & 2017 & 2018 & 2019 & 2020 & 2021 \\
\hline Uddevalla & Ljungskile & & & & & $\mathrm{P}$ \\
\hline \multirow[t]{2}{*}{ Kungälv } & Tofta kile & & & & $P$ & \\
\hline & Harestad & & & & & $\mathrm{T}$ \\
\hline \multirow[t]{7}{*}{ Kungsbacka } & Hjälm 1 & & $\begin{array}{l}\text { H (2 kullar } \\
\text { clutches) }\end{array}$ & $\begin{array}{l}\text { H (2 kullar } \\
\text { clutches) }\end{array}$ & $\mathrm{H}$ & $\begin{array}{l}\text { H (2 kullar } \\
\text { clutches) }\end{array}$ \\
\hline & Hjälm 2 & & $P$ & & $P$ & $\mathrm{P}$ \\
\hline & Svinholmen & & & $\mathrm{T}$ & & \\
\hline & Forsbäck & & & & & $\mathrm{H}$ \\
\hline & Tjolöholm & & & & $\mathrm{T}$ & \\
\hline & Skällträ & & & & & $\mathrm{T}$ \\
\hline & Löftaån & & & & $\mathrm{P}$ & \\
\hline \multirow[t]{11}{*}{ Varberg } & Viskan 1 & & & $\mathrm{~T}$ & $P$ & $P$ \\
\hline & Viskan 2 & & & & $\mathrm{P}$ & \\
\hline & Årnäs 1 & & & & $\mathrm{H}$ & $P$ \\
\hline & Årnäs 2 & & & & & $P$ \\
\hline & Kärrastrand & & & & & $\mathrm{T}$ \\
\hline & N. Uddarna & & & & & $\mathrm{T}$ \\
\hline & Getterön 1 & $P$ & & & $\mathrm{~T}$ & $\mathrm{P}$ \\
\hline & Getterön 2 & $\mathrm{~T}$ & & & & \\
\hline & Björkäng & & & & & $\begin{array}{l}\mathrm{H} \text { (2 kullar } \\
\text { clutches) }\end{array}$ \\
\hline & Törlan 1 & & & & $\mathrm{H}$ & $\mathrm{P}$ \\
\hline & Törlan 2 & & & & & $P$ \\
\hline
\end{tabular}


TABELL 1 fortsatt | Table 1 continued.

\begin{tabular}{|c|c|c|c|c|c|c|}
\hline $\begin{array}{l}\text { Kommun } \\
\text { Municipality }\end{array}$ & $\begin{array}{l}\text { Lokal } \\
\text { Site }\end{array}$ & 2017 & 2018 & 2019 & 2020 & 2021 \\
\hline \multirow[t]{4}{*}{ Falkenberg } & Agervik & & & & $P$ & \\
\hline & Lis mosse & & & $\mathrm{P}$ & & \\
\hline & N. Lyngen & & & & & $\mathrm{T}$ \\
\hline & Vassvik & & & & & $\mathrm{H}$ \\
\hline Halmstad & Hamnen & $P$ & & & & \\
\hline Laholm & Lagaoset & & & & $\mathrm{T}$ & \\
\hline Laholm & Skottorps våtmark & & & $\mathrm{T}$ & & \\
\hline \multicolumn{2}{|c|}{$\mathrm{N}$ tillfälligt sjungande temporarily singing } & 1 & 0 & 3 & 3 & 5 \\
\hline \multicolumn{2}{|c|}{ N permanent sångrevir permanent song territory } & 2 & 1 & 1 & 6 & 8 \\
\hline \multicolumn{2}{|c|}{ N säkerställd häckning confirmed breeding } & 0 & 1 & 1 & 3 & 4 \\
\hline \multicolumn{2}{|l|}{$\mathrm{N}$ totalt total } & 3 & 2 & 5 & 12 & 17 \\
\hline
\end{tabular}

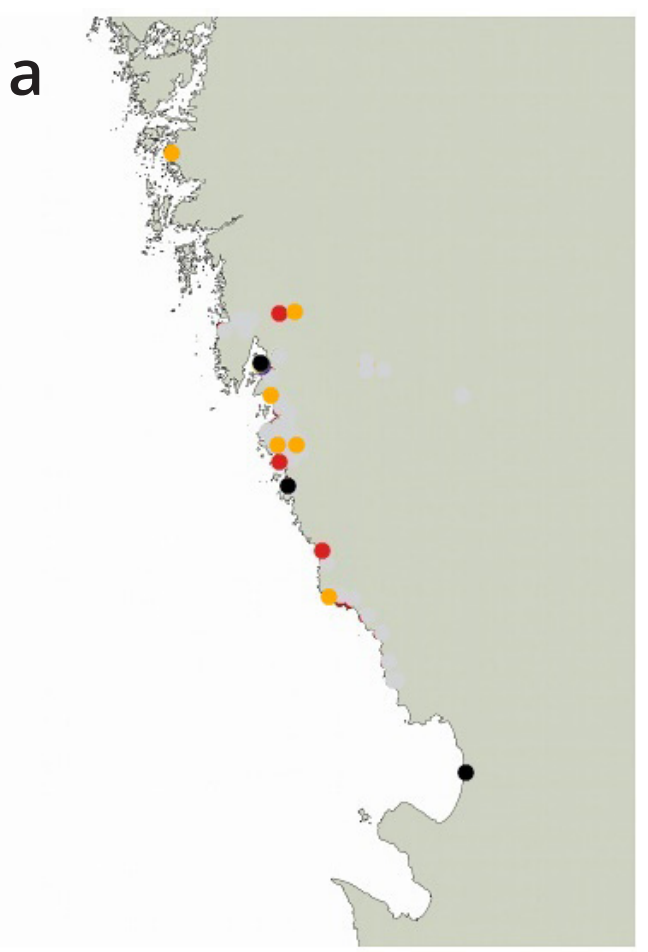

b

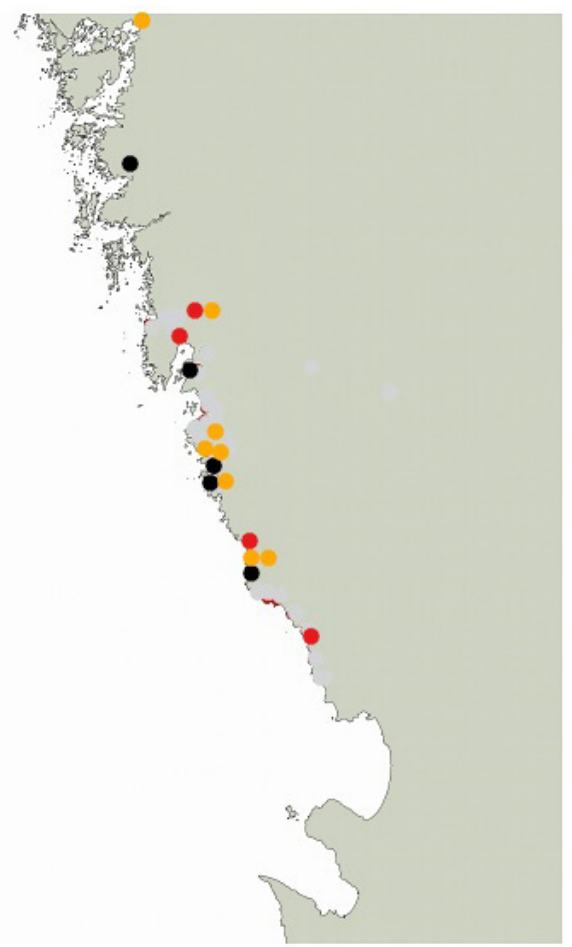

FIGUR 3. Geografisk utbredning av sjungande hannar av vitstjärnig blåhake Luscinia svecica cyanecula: (a) 12 under 2020 och (b) 17 under 2021. Svarta punkter indikerar tillfälligt sjungande hannar, gula permanent sångrevir och röda säkerställda häckningar. Kartan är ett utsnitt av svenska Västkusten, från Stenungsund i norr till Höganäs i söder (nordligaste punkten på kustlinjen vid $58^{\circ} 12^{\prime} \mathrm{N} 11^{\circ} 33^{\prime} \mathrm{E}$ och sydligaste vid $56^{\circ} 18^{\prime} \mathrm{N}$ $\left.12^{\circ} 56^{\prime} \mathrm{E}\right)$.

- Geographic distribution of singing White-spotted Bluethroat Luscinia svecica cyanecula males: (a) 12 in 2020 and (b) 17 in 2021. Black circles indicate temporarily singing males, yellow permanent song territories, and red confirmed breedings. The map shows a part of the Swedish West Coast from Stenungsund in the north to Höganäs in the south (with the northernmost point of the coastline at $58^{\circ} 12^{\prime} \mathrm{N}$ $11^{\circ} 33^{\prime} \mathrm{E}$ and the southernmost point at $\left.56^{\circ} 18^{\prime} \mathrm{N} 12^{\circ} 56^{\prime} \mathrm{E}\right)$. 


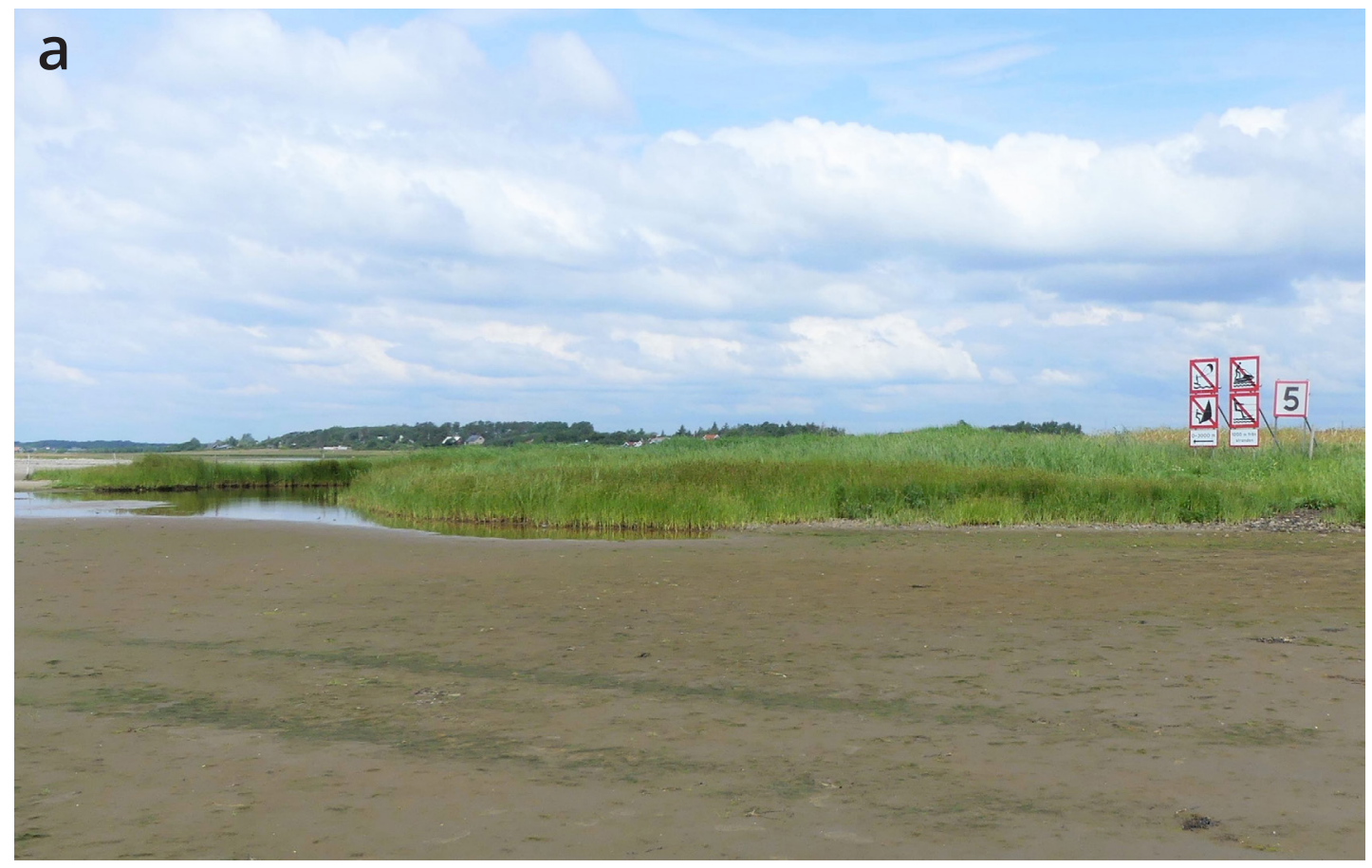

b

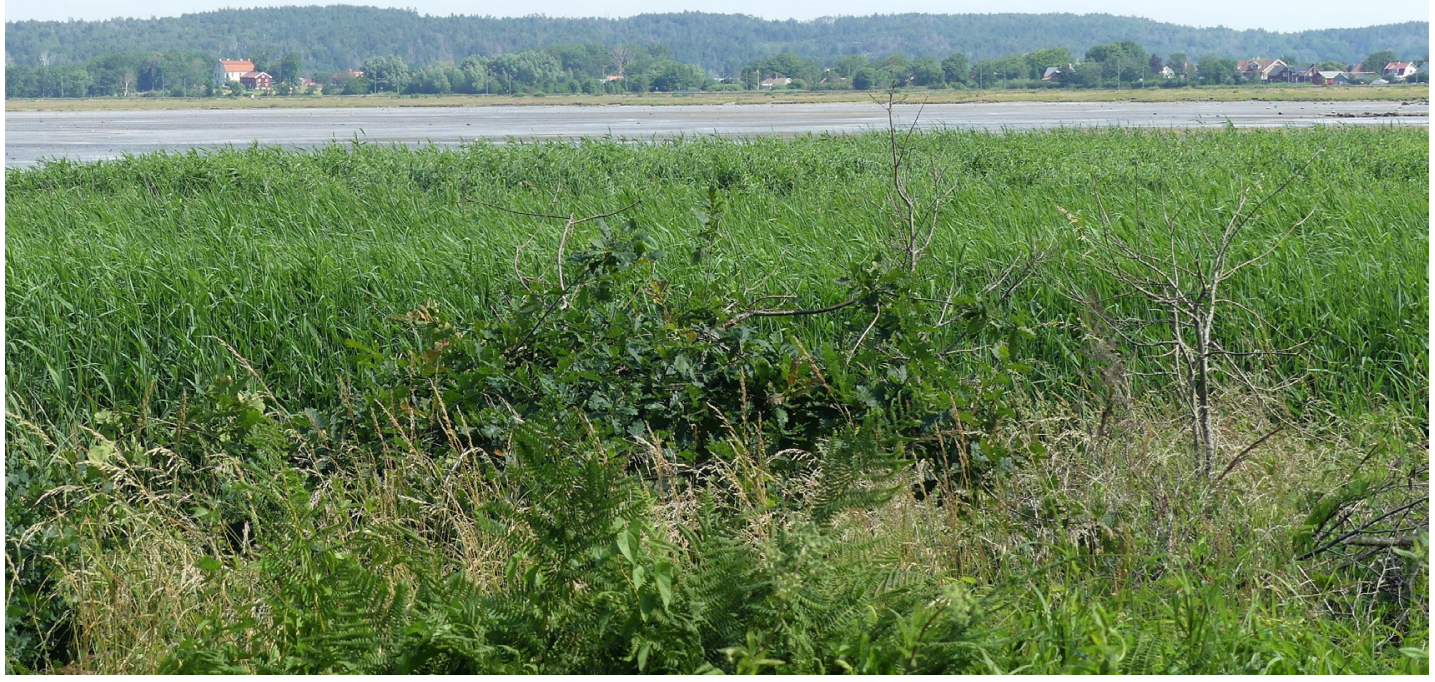

FIGUR 4. Häckningsmiljöer för vitstjärnig blåhake Luscinia svecica cyanecula vid (a) Björkängs camping och (b) Årnäs i Halland. Foto: A. Andersson. - Breeding sites for White-spotted Bluethroat Luscinia svecica cyanecula at (a) Björkäng and (b) Årnäs in Halland. Photo: Anette Andersson. 
tidigare beskrivits för Lagaoset (tabell 1 , figur 2, $3 \mathrm{~b}$ ). Dessutom fångades en hona med ruvfläck på Nidingen 18 juni.

\section{Diskussion}

Av resultaten framgår att 39 sjungande hannar registrerades under femårsperioden 2017-2021 (tabell 1), samtliga i habitat som innehåller bladvass Phragmites australis (figur 4). Tolv av dem utgjordes av tillfälligt sjungande hannar, 18 permanenta sångrevir och nio av säkerställda häckningar. Dessutom tillkommer fyra kullar som klassats som andrakullar. Därmed har sammantaget 13 ungkullar kunnat lokaliseras. Med tanke på att endast en sjungande hanne tidigare noterats på Västkusten fram till 2016 får detta anses vara en dramatisk utveckling.
Majoriteten anlände i mitten av april, även om enstaka hannar kunde dyka upp en bit in i maj (figur 2). Om de tillfälligt uppträdande hannarna dragit vidare i området eller hållit sig dolda från observationer är ovisst. Normala år sjunger de då ljudligt främst nattetid, men även mitt på dagen kan vissa hannar uppvisa en hög sångaktivitet. Under den kyliga våren 2021 var däremot den spontana sångaktiviteten påfallande låg. En erfarenhet av inventeringarna denna vår, är betydelsen av uppspelad sång för att öka effektiviteten till upptäckt.

Trots att expansionen ännu är i sitt inledningsskede torde det finnas åtminstone ett trettiotal revir av vitstjärnig blåhake i landet. Då de lätt kan förbises till följd av sina undangömda levnadsvanor, kan man förmoda att mörkertalet är betydande. I Sverige finns det riklig tillgång på lämpliga våtmarksmiljöer, som förmodligen kommer att besättas i en ökande takt under de kommande åren.

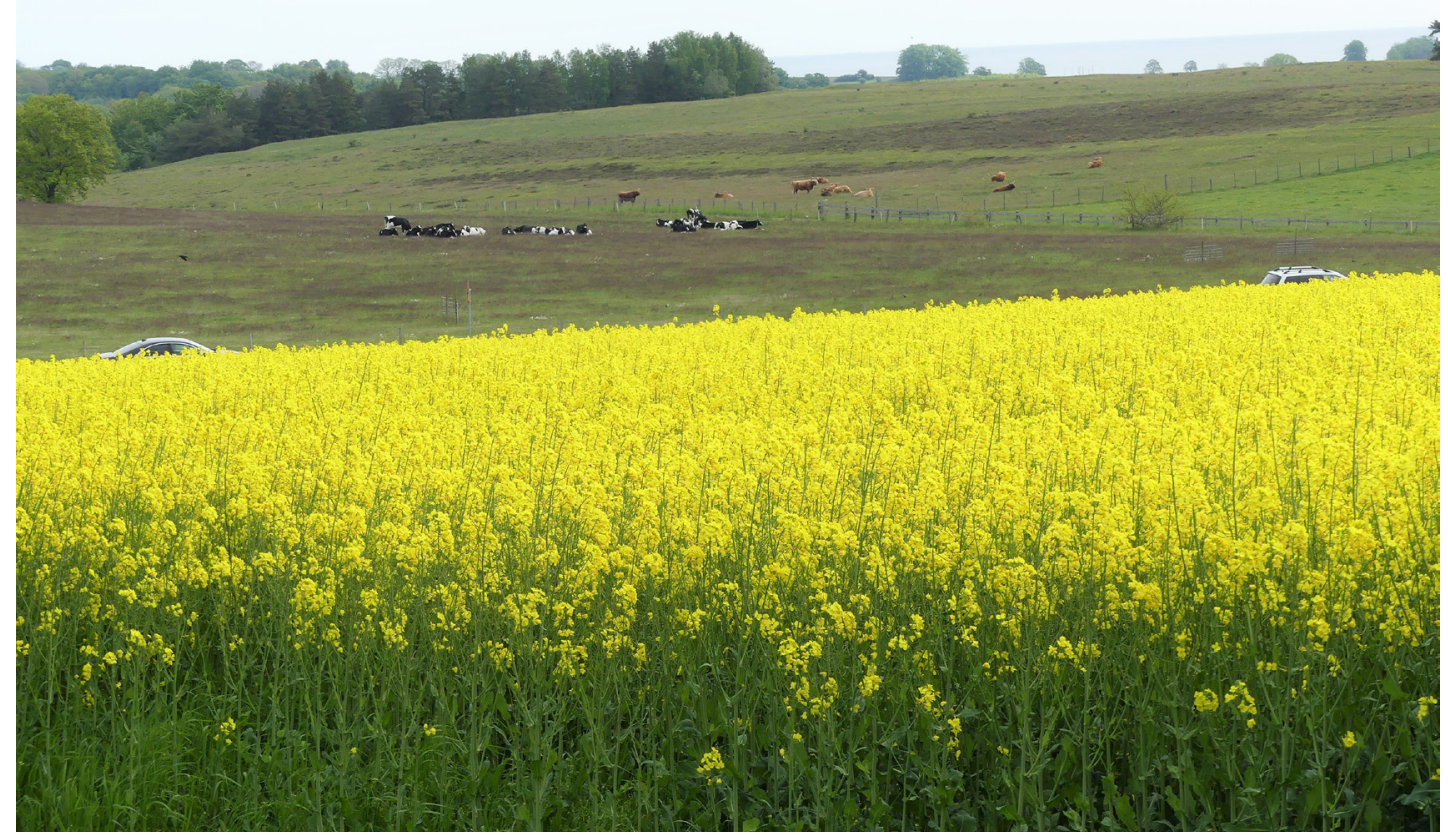

FIGUR 5. Kan utbredningen av rapsfält bli avgörande för den vitstjärniga blåhakens Luscinia svecica cyanecula framtida etablering i Sverige? Foto: Anette Andersson.

- Can the distribution of rapeseed fields be important for the future establishment of White-spotted Bluethroats Luscinia svecica cyanecula in Sweden? Photo: Anette Andersson. 
Att döma av utvecklingen i Tyskland, Nederländerna och Danmark (Gedeon m. fl. 2014, van Kleunen m. fl. 2017, Vikstrøm \& Moshøj 2020), har denna underart en stor potential till fortsatt spridning. Vid inventeringar bland annat i nordvästra Tyskland, återfanns majoriteten av de sjungande hannarna och häckande paren $\mathrm{i}$ odlingsmiljöer. Av dem utgjordes drygt $40 \%$ av rapsfält. Enligt Kruger (2002) och Kruger m. fl. (2005) talar mycket för att det i själva verket är rapsfältens ökade utbredning under de senaste decennierna, som varit en av huvudorsakerna till den vitstjärniga blåhakens kraftiga populationstillväxt. Uppträdandet i raps förefaller således vara av särskilt intresse även för den svenska utvecklingen framöver (figur 5). Det gäller kanske framför allt i Skåne där rapsfälten är vidsträckta och täcker stora arealer. Kanske blir dessa jordbrukslandskap avgörande för hur framgångsrik den vitstjärniga blåhakens etablering kommer att bli i de nyerövrade skandinaviska randområdena.

\section{Tack}

Stort tack till Leif Klinteroth, Sören Svensson och Anders Nothagen för granskning av manuskriptet. Tack också till alla som varit ute och letat eller bidragit med rapporter på Artportalen.

\section{Referenser}

Andersson R. 2019. Populationsutveckling hos svarthakad buskskvätta Saxicola rubicola under expansionens inledningsskede i Västsverige. Ornis Svecica 29: 26-36. https://doi.org/10.34080/ os.v29.19555

Andersson R. 2021a. Rapportera vitstjärnig blåhake. Vår Fågelvärld $80(1): 10$.

Andersson R. 2021b. Inventering av vitstjärnig blåhake i Halland 2021. Fåglar $i$ Halland 2020: 6-7.

Duivendijk NV. 2011. Advanced Bird ID Handbook. New Holland Publishers, London, Storbritannien.

Gedeon K, Gruneberg C, Mitschke A \& Sudfeldt C. 2014. Atlas Deutscher Brutvogelarten. Stiftung Vogelmonitoring Deutschland und Dachverband Deutscher Avifaunisten, Munster, Tyskland.
Glutz von Blotzheim UN \& Bauer KM. 1988. Handbuch der Vögel Mitteleuropas. Vol. 11/1. AULA-Verlag, Wiesbaden, Tyskland.

Haas F, Barbet-Massin M, Green M, Jiguet F \& Lindström Å. 2014. Species turnover in the Swedish bird fauna 1850-2009 and a forecast for 2050. Ornis Svecica 24: 106-108. https://doi.org/10.34080/ os.v24.19602

Huntley B, Green RE, Collingham YC \& Willis SG. 2007. A climatic atlas of European breeding birds. Lynx Edicions, Barcelona, Spanien.

Johnsen A, Andersson S, Fernandez JG, Kempenaers B, Pavel V, Questiau S, Raess M, Rindal E \& Lifjeld JT. 20o6. Molecular and phenotypic divergence in the bluethroat (Luscinia svecica) subspecies complex. Molecular Ecology 15: 4033-4047. https://doi. org/10.1111/j.1365-294X.2006.03075.x

Klinteroth L. 2015. Ny stjärna på himlen. Vår Fågelvärld 74 (4): 14-18.

Klinteroth L. 2021. Farhultsvikens "vitstjärniga" 2014-2020. Anser 6o: 47-52.

Kruger T. 2002. Verbreitung, Bestand und Habitatwahl des Blaukehlchens (Luscinia svecica cyanecula) in Niedersachsen 2001: Ergebnisse einer landesweiten Erfassung. Vogelkundliche Berichte aus Niedersachsen 34: 1-21.

Kruger T, Petersen B \& Zang H. 2005. Blaukehlchen - Luscinia svecica (L., 1758). Sid 50-62 i: Die Vögel Niedersachsens und des Landes Bremen (Zang H, Heckenroth H \& Südbeck P, red). Niedersächsischer Landesbetrieb für Wasserwirtschaft, Küsten- und Naturschutz, Norden, Tyskland.

Magnander K. 2021. När häckar vitstjärnig blåhake i Göteborg? Fåglar på Västkusten 55 (2): 2.

Nyegaard T, Meltofte H, Tofft J \& Grell MB. 2014. Truede og sjaeldne ynglefugle i Danmark 1998-2012. Dansk Ornitologisk Forenings Tidsskrift 108: 1-144.

Nord M. 2017. Vitstjärnig blåhake på Getterön 2017. Fåglar i Halland 2017: 9-10.

Rosenberg E. 1943. Vitstjärnig blåhake - ny för Sverige - iakttagen vid Oset. Vår Fågelvärld 2: 93.

Shirihai H \& Svensson L. 2018. Handbook of Western Palearctic Birds. Passerines. Helm, London, Storbritannien.

Svensson S, Svensson M \& Tjernberg M. 1999. Svensk fågelatlas. Vår Fågelvärld, supplement 31. Sveriges Ornitologiska Förening, Stockholm.

van Kleunen A, Foppen R \& van Turnhout C. 2017. Basisrapport voor de Rode Lijst Vogels 2016 volgens Nederlandse en IUCN-criteria. Sovon-rapport 2017/34. Sovon Vogelonderzoek Nederland, Nijmegen, Nederländerna. https://www.sovon.nl/sites/default/ files/doc/rap_2017-34_basisrapport-rode-lijst-2016.pdf

Vikstrøm T. \& Moshøj CM. 2020. Fugleatlas, de danske ynglefugles udbredelse 2014-2017. Dansk Ornitologisk Forening \& Lindhardt og Ringhof, Köpenhamn, Danmark. 


\section{English summary}

White-spotted Bluethroat Luscinia svecica cyanecula is the latest addition to the Swedish bird fauna, with the first breeding in Scania 2015 (Klinteroth 2015, 2021). Until 2014, there was a total of 58 records in the country (https://birdlife.se/rk/raritetskatalogen), the first one as late as 1943 (Rosenberg 1943). Along the Swedish West Coast (Göteborg/Bohuslän, Halland), there were only three records until 2016 and the first breeding was reported in 2018 (https://birdlife.se/rk/ raritetskatalogen).

The aim of this paper is to document the process of the immigration during the breeding season (AprilJuly) on the Swedish West Coast during the last fiveyear period (2017-2021). Special emphasis is put on the breeding seasons 2020 and 2021, as various degrees of systematic surveying (with playback) was conducted. In addition to this, I have made use of spontaneous sightings reported to the database Artportalen (https:// www.artportalen.se, accessed July 2021).

The reliability of the plumage characters in cyanecula and other subspecies (e.g. the white throat spot) has been discussed in various contexts (e.g. Glutz von Blotzheim \& Bauer 1988, Johnsen et al. 2006, Duivendijk 2011, Shirihai \& Svensson 2018). As there is some variation and overlap, some individuals on the West Coast could theoretically belong to the svecica group. Based on distribution and habitat choice, however, this seems highly unlikely. All males (with associated females; Figure 1) in this material, which have appeared with a white throat spot in reedbeds and wetland habitats, are thus treated as cyanecula.

The findings are divided into three categories: temporarily singing males (less than one week), permanent song territories (one week or more), and confirmed breeding (following the criteria in Svensson et al. 1999). The details of all 39 singing males 2017-2021 are presented in Table 1, the arrival date for 32 singing males in Figure 2, and the geographic distribution 2020 and 2021 in Figure 3. Examples of breeding sites are shown in Figure 4.

The Swedish expansion should be seen in the context of Danish immigration in combination with a large-scale advance via the Netherlands and Germany (Gedeon et al. 2014, van Kleunen et al. 2017, Vikstrøm \& Moshøj 2020). The White-spotted Bluethroat belongs to the taxa whose range expansions are commonly associated with climate change, and the Swedish population is expected to increase according to predictions of the composition of the future bird fauna (Huntley et al. 2007, Haas et al. 2014). Due to a warmer climate and plenty of appropriate habitats, not least rapeseed Brassica napus fields (Figure 5; Kruger 2002, Kruger et al. 2016), the conditions favour a continued range expansion in southern Sweden.

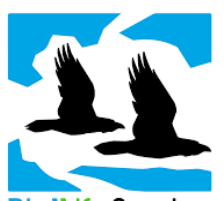

Birdlife Sverige

Ornis Svecica (ISSN 2003-2633) is an open access, peer-reviewed scientific journal published in English and Swedish by BirdLife Sweden. It covers all aspects of ornithology, and welcomes contributions from scientists as well as non-professional ornithologists. Accepted articles are published at no charge to the authors. Read papers or make a submission at os.birdlife.se.

Ornis Svecica (ISSN 2003-2633) är en fritt tillgänglig granskad vetenskaplig tidskrift som ges ut på svenska och engelska av BirdLife Sverige. Den täcker ornitologins alla områden och välkomnar bidrag från såväl forskare som icke-professionella ornitologer. Accepterade uppsatser publiceras utan kostnad för författarna. Läs uppsatser eller skicka in ditt bidrag på os.birdlife.se. 